\title{
Long term results of permanent epicardial pacing in neonates and infants
}

\author{
Sungkyu Cho*, Woong-Han Kim, Kwanyong Hyun, Ji Young Park, Jeong Ryul Lee, Yong Jin Kim \\ From World Society of Cardiothoracic Surgeons 25th Anniversary Congress, Edinburgh \\ Edinburgh, UK. 19-22 September 2015
}

\section{Background/Introduction}

Despite the improvement of transvenous leads, the open surgical implantation of epicardial leads in neonates and infants remains essential.

\section{Aims/Objectives}

We reviewed the long term outcomes after epicardial pacemaker implantation in neonates and infants.

\section{Method}

From 1989 to 2013, 44 patients (15 neonates) underwent pacemaker implantation within the first year of life. The mean age and weight were $101.2 \pm 97.2$ days and $4.8 \pm 1.8 \mathrm{~kg}$ at the time of pacemaker implantation. The Indication for pacemaker implantation were postoperative atrioventricular block in 23, congenital atrioventricular block in 16, sinus node dysfunction in 4 , and myocarditis induced atrioventricular block in 1. Unipolar epicardial leads (non steroid eluting: 22, steroid eluting: 22) were inserted through median sternotomy or subxyphoid approach.

\section{Results}

Mean follow up duration was $9.1 \pm 7.9$ years. The most commonly used generator mode at first implantation was VVI, which was used in $52.3 \%(\mathrm{n}=23)$. There were generator mode changes from initial VVI or VVIR to dual chamber pacing in 11 patients, mean $7.0 \pm 6.2$ years later, due to ventricular dysfunction and dyssynchrony. Freedom from the need for generator replacement was $95.0 \%, \%, 70.1 \%, 21.7 \%$ at $1,5,10$ years. And, the median longevity of the generators was 6.5 years. 15 lead malfunction (34.1\%) events were detected, 5 of

\footnotetext{
Seoul National University Children's Hospital Department of Thoracic and Cardiovascular Surgery, Seoul National University College of Medicine Seoul National University Hospital, Seoul National University Children's Hospital 101 Daehangno, Jongno-Gu, Seoul, 110-744, Korea
}

which were due to lead fracture and 1 of which was due to lead infection. Freedom from the need for lead replacement was $97.6 \%, 75.7 \%, 47.7 \%$ at $1,5,10$ years. The lead replacement rate is significantly higher in patients who underwent non steroid eluting lead implantation $(\mathrm{p}=0.033)$. The median longevity of the leads was 9.1 years.

\section{Discussion/Conclusion}

In neonates and infants, more frequent pacemaker generator or lead changes are needed because of high pacing rates, complete pacemaker dependency and rapid somatic growth. The use of steroid eluting leads increased lead longevity and decreased the need for surgical reinterventions. Epicardial pacing is feasible, safe, and effective in neonates and infants.

Published: 16 December 2015

doi:10.1186/1749-8090-10-S1-A207

Cite this article as: Cho et al:: Long term results of permanent epicardial pacing in neonates and infants. Journal of Cardiothoracic Surgery 2015 10(Suppl 1):A207.

Submit your next manuscript to BioMed Central and take full advantage of:

- Convenient online submission

- Thorough peer review

- No space constraints or color figure charges

- Immediate publication on acceptance

- Inclusion in PubMed, CAS, Scopus and Google Scholar

- Research which is freely available for redistribution

Submit your manuscript at www.biomedcentral.com/submit

\section{() Biomed Central}

